\title{
Cultural Influences on Opinion Expression in an Online and Offline Context
}

\author{
Fahed Al-Sumait | ORCID: 0000-0001-9756-7924 \\ Corresponding author \\ Gulf University for Science and Technology, Hawally, Kuwait \\ alsumait.f@gust.edu.kw \\ Edward Frederick | ORCID: 0000-0001-5504-296X \\ Greenhill Center of the Arts, University of Wisconsin-Whitewater, \\ Whitewater, Wisconsin, US \\ frederie@uww.edu
}

Ali Al-Kandari | ORCID: 0000-0002-8552-6196
Gulf University for Science and Technology, Hawally, Kuwait
alkandari.j@gust.edu.kw

Ahmad Sharif

Department of Mass Communication, Kuwait University, Safat, Kuwait yesahmad@hotmail.com

\begin{abstract}
This study compares the expression of opinion in incongruent offline and online settings regarding the issue of gender desegregation in Kuwait's public schools. Spiral of silence theory provides the theoretical foundation for examining the impact of certain cultural factors and religious influences on the expression of opinion, their relationship to the fundamental tenets of the theory, such as fear of social isolation, and Twitter use variables among respondents to a survey. The results to a questionnaire administered to 534 public and private university students indicate greater overall expression of opinion in the offline than online context. Offline and online, the nonconformist personality variable was a positive predictor of expression of opinion, and fear of social isolation was a negative predictor. The perceived position of Islam on the issue was a predictor of expression of opinion only in the offline context. Finally,
\end{abstract}


daily average use of Twitter was an additional predictor of expression of opinion in the online environment.

\section{Keywords}

expression of opinion - gender desegregation - Kuwait - online and offline contexts spiral of silence

\section{Introduction}

Scholars have increasingly examined the impacts of online media on opinion expression in democratic countries (e.g. Rani \& Sumathy 2018). Despite the value of assessing expression of opinion in free and consolidated democracies, as is typically the case, explorations of the willingness to express opinions in non-democratic settings remain limited. Examinations of people's communication behaviours under alternative political systems can help demonstrate whether the exchange of opinions online can engender alternative political impacts in settings in which citizens might desire greater levels of political engagement.

Furthermore, much of the literature on the expression of opinion, whether in offline or online contexts, reflects profiles in countries where dominant forms of acculturation could be characterized as a preference for individualistic cultural values (e.g. Scheufele \& Moy 200o). Sociocultural norms on individual expression are regulated differently in the Arab region than in more individualistically-oriented societies. For example, Islamic religious restrictions imposed by both the state and society can further limit the expression of minority viewpoints and intensify fear about offering religiously unacceptable opinions (Kamali 1997). Within the context of authoritarianism, restrictions on traditional mass media compound these sociocultural conditions in ways that affect public opinion expression. Under circumstances, many people in many Arab societies risk social isolation when expressing opinions that might deviate from group norms.

This study employs the spiral of silence (sos) theory because it is well suited for exploring how, why, and when individuals choose to express their opinions about controversial issues. Its basic tenets argue that audiences see the opinions presented in the media as representative of the dominant public sentiment, regardless of whether they actually are (Scheufele \& Moy 2000). 
The theory predicts that most audience members, except for a few strongly determined individuals, will be hesitant to express opinions that are incongruent with those dominating the media or may express opinions that are congruent with those in the media, even if those views are inconsistent with their true feelings, out of fear of social isolation (e.g. Ho \& McLeod 2008).

Like other sos research that examines controversial issues, this study uses gender desegregation in public schools to compare the willingness of residents in Kuwait to express opinions in an online environment against their willingness to share opinions about the same topic in an offline environment. To do this, it explores the impact of cultural conformity, religiosity, Twitter-use variables, and traditional sos theoretical components, including the fear of social isolation and perceptions of current and future opinion climates, on Kuwaitis' willingness to express their opinions both offline and online.

Kuwaiti Cultural Norms and Gender Desegregation in Public Schools

Kuwait is a constitutional emirate that divides power among a judicial branch, an elected national assembly, and an emir. The emir exercises his monarchical authority through an unelected executive cabinet. Compared to established liberal democracies, Kuwait's political system gives its citizens less power, though the level of political freedom is still considered among the highest in the region because of its relatively liberal constitution and active parliamentary system (Herb 1999; Tetreault 2000). Kuwait's dominant culture places significant value on group cohesion and consensus. Accordingly, individuals face sociopolitical constraints on their free expression (see Dalisay 2012). Moreover, as an Islamic society, citizens with conservative interpretations of Islam can encourage submission and subjugation to established doctrines in a way that can greatly influence followers to refrain from expressing contradictory opinions (Barakat 1993).

However, emerging media technologies are transforming the cultural norms of behaviour in Kuwait, just as they do elsewhere. The Arab Social Media Report (Salem 2017), looking at Twitter, the platform of interest in this study, indicates that from 2011 to 2017 Kuwait had the highest Twitter penetration rate of any Arab country, with the most active users tweeting an average of 4.2 times a day. Twitter, in particular, has demonstrated exceptionally high early adoption rates in Kuwait because of its political utility and discussion-oriented nature (Rani \& Sumathy 2018). In 2009, three years after its launch, it was 
already the digital platform of choice for candidates in Kuwaiti parliamentary elections across the ideological spectrum, including Kuwait's first successful female parliamentarians, who used it to circumvent biases in traditional mass media (Al-Sumait 2014). In short, Kuwait represents a highly saturated environment for platforms such as Twitter, which can also serve important sociopolitical functions. This raises questions about the impact of a changing digital landscape on people's propensity to express public opinions, regardless of the ideas' perceived popularity in an offline context.

We chose the topic of gender desegregation in public schools to provide a preliminary evaluation of the expression of opinions in Kuwait because of its frequency in public debate. In Kuwait, gender segregation is practiced in many public places, including mosques, public medical facilities, health clubs, salons, and other settings (AlMatrouk 2016). Traditionally, men and women lead separate lifestyles beginning in early childhood, when unrelated boys and girls are segregated in school, extracurricular activities, and most social gatherings.

The country's public education system is a key location for the enculturation of gender norms, as male and female students, teachers, and school administrators are segregated, as has been the practice since the first school for girls was established in 1937-1938, one year after boys' schools were established. However, the number of girls who enrolled in public school did not surpass four thousand for about two decades because of the cultural and religious objections to female education by many families. During the 1960 os and 1970s, women commonly chose educational majors that emphasized the arts and humanities, rather than more vocationally oriented tracks, because many did not expect to enter the workforce. Social pressure for women to occupy traditional roles as homemakers and caregivers remained high, contributing to a scarcity of female role models serving in government, industry, and higher education.

Even though university education was co-educational, in 1996 the parliament, which had an Islamist-leaning majority, voted for gender segregation in all schools and universities. Many have stated that this law was an arrangement with the government intended to quell the many other demands of the Islamist-leaning members of parliament who wanted to impose various Islamic laws and regulations. As Herb (2002) described, Islamists in Kuwait's parliament have regularly taken illiberal policy stances on religious and women's issues, at times even against the ruling emir, as when they rejected the emir's 1999 proposal for female suffrage. In this climate, the segregation law was passed with an exception for private schools, based on the logic that many private schools were established to serve non-Kuwaiti expatriates and were 
thus left to manage their enrolment and segregation policies in accordance with their own traditions (Algharabali 2010).

Gender desegregation in schools has been a controversial issue in Kuwait, with two distinct camps. From the conservative viewpoint, this segregation is required to protect family honour by preventing situations in which men and women could mix outside of a family setting. From this perspective, these situations raise doubts or suspicions about the intentions and behaviours of both sexes. Even platonic friendships across genders can sometimes create negative social impressions and damage familial and tribal reputations (Abadeer 2015). In the second camp many Kuwaitis who believe that segregating schools by genders has been influenced too heavily by cultural conservatism and politicized religious interpretations. These people often acknowledge that many families originally opposed basic education for girls and women until the early 1900 s but later came to accept the practice. They also point out that gender mixing in private schools has not produced disproportionate immoral behaviour and that women now contribute to all types of professions, even those in which genders intermingle (Al-Houlan 2015). Many other scholars have also mentioned that Islam does not impose segregation but, rather, regulates the level of interaction between the genders, stating that men and women worship side by side in the holiest mosque, the Kaaba, in Mecca. Others argue against the hypocrisy over the law, which segregates local universities by gender while the government provides scholarships for Kuwaiti females to study abroad in mixed-gender settings (Dinkha et al. 2010). This perspective is further reinforced by data from the World Economic Forum's (2021) Global Gender Gap Index, which lists Kuwait as having the narrowest gender gap in educational attainment of all Arab countries, ranking 59 of 156 worldwide, just above Poland and Sweden. In view of these competing perspectives, gender desegregation is an issue on which strong opinions are held by those on both sides of the debate, though the conservative view currently predominates in public.

\section{Cultural Norms and Religion as Predictors of Offline} Opinion Expression

In describing the common cultural norms in Kuwait, we do not seek to essentialize the cultural environment as homogeneous (or dichotomous) or ignore contextual specificity; the concerns about doing so have been well described elsewhere (see e.g. Fiske's [2002] comment on Oyserman et al. [2002] about the empirical limitations inherent in the use of the individualism and collectivism 
constructs). Rather, the aim is to describe, for those unfamiliar with Kuwait, important dominant features of the contemporary environment with a bearing on the issue of expressing opinions about gender segregation against which our conception of nonconformity is positioned.

Repression of opinion seems more likely to occur in contexts where dominant acculturation emphasizes group unity and interdependence than those in which individualistic values and norms foster a greater independence against group intrusion (Huang 2005). In locations where people widely share similar values and create strong social pressure toward collectivist behaviour, they tend to conform to the majority opinion to avoid social punishment (Dalisay et al. 2012; Huang 2005). In Kuwait, the dominant mores of society promote family consensus and loyalty. Notions of individualism are less important than family interconnectedness because 'the self is defined as an appendage of the collective, and an individual's identity is associated with social affiliation to the family or tribe rather than to personal qualities or achievements' (Dwairy 2006: 6). Due to the strong presence of culturally conservative beliefs, which suppose, for example, that unrestrained relationships at school with those of a different gender could tarnish the group or tribal image, many conformist Kuwaitis remain silent in an incongruent social setting or express opinions in line with this belief to avoid social isolation.

However, research in Kuwait has demonstrated that many young university students, who form the sample in this study, express nonconformist, modernist, and 'liberal' ideals more freely than people in older generations (Abdulrahim et al. 2009). They often exhibit more 'progressive' opinions, frequently consume English-language media, may embrace a more liberal outlook on life, are more accepting of equal gender roles (ibid.), and hold a more globalized perspective than others in the country (Hasanen et al. 2014). These behaviours could be characterized as nonconformist based on their positionality vis-à-vis the dominant cultural norms. As such, young people can be seen as more independent in their beliefs and preferences on average and influenced by personal attitudinal control more than cultural conformity. They seem to be more likely to confront dominant opinions despite the potential cultural risks (Abadeer 2015). Young people are more inclined to be 'hard-line' opinion holders, who, regardless of social penalties, are predicted to express opinions publicly (Dalisay 2012; Willnat et al. 2002). As a result, the first hypothesis posited in this study is as follows:

Hypothesis 1: Cultural nonconformists are more likely than cultural conformists to express their opinions on gender desegregation in an incongruent offline opinion climate. 
For the majority of Arab populations, the role of Islam is a particularly salient factor in social life (Kamali 1997). This might be of special importance in a study on Kuwaiti society. A World Values Survey in 2014 found that 86 percent of Kuwaitis believe that religion is very important in their lives, compared with the world average of 49 percent. The majority also reported that, in a conflict between religion and science, they would accept the religious explanation as correct (World Values Survey 2014).

In the present study, two sets of circumstances might emerge. Those who are certain about Islam's position on the issue of gender desegregation will be more audacious in expressing their opinions because they speak with a presumed knowledge about the associated religious instructions and those who are uncertain where Islam stands will be more likely to abstain from offering an opinion because they believe that expressing an opinion which is not religiously supported can make them feel disobedient to the religion or leave them open to social sanctioning and labelling. Indeed, Wyatt et al. (1996) found that Arab respondents said that their first reason for not expressing certain opinions was fear of punishment by God. Accordingly, we posit a second hypothesis:

Hypothesis 2: Certainty about the perspective of Islam on gender desegregation in public schools will predict the expression of opinions in an incongruent offline opinion climate.

\section{4 sos Theoretical Components as Predictors of Offline Contexts}

According to the sos theory, fear of social isolation is the main driving force behind shunning unpopular opinions (Scheufele \& Moy 2000). The theory also indicates the role of current and future perceptions of dominant opinion climates. People tend to be more expressive of their true opinions if they perceive that they are similar to opinions held by the current majority or that their opinion will gain popularity in the future (ibid.).

Because they often belong to cultures that Hofstede (2018) and the World Values Survey (2014) would characterize as valuing collectivism over individualism, Arabs in general try to avoid deviation from cultural conventions. Dwairy (2006: 73) argues that 'independency and lack of conformity are considered a kind of carelessness or egoism in Arab/Muslim societies and are recipes for recurrent conflict and social rejection'. Social isolation can be costly to a Kuwaiti because the individual will feel a strong need to identify with a group (Laffin 1975). Because of the great influence of culture and a fear of social 
isolation, many Arabs are very observant of the distribution of opinions in a public opinion climate. Laffin describes the importance of the dominant public view in a predominantly Arab culture. 'Public opinion is the main force that society judges, praises or condemns.... Since internal freedom he [she] enjoys is very slight, he [she] is constantly watching for the opinions of his [her] community' (Laffin 1975: 90). Accordingly, we posit the following hypotheses:

Hypothesis 3: Fear of social isolation negatively predicts the expression of opinion in an incongruent offline context.

Hypothesis 4: Perceived congruency of current and future opinion climates positively predicts the expression of opinion in an incongruent offline context.

Scholars who have explored the expression of opinion in online contexts present diverging scenarios on how it is affected by online communication platforms. The first scenario, which might be characterized as 'cyber-optimist', argues that online platforms encourage the expression of opinion because people can avoid stressful and threating face-to-face situations. Online anonymity and privacy settings reduce social cues and group pressure and increase autonomy. These might aid in the expression of opinion even if the opinion is not consistent with that of the majority (see e.g. Kown et al. 2015). The formation of online groups and communities reduces fear about standing out individually. A lack of social cues online can also create 'an egalitarian pattern of interaction' (Elshahed 2014: 48) that reduces the framing of individuals in online settings and thus liberates them to express their opinions. Our study argues that the 'cyber-optimist' scenario can occur if and when respondents are eager to express their opinions on controversial topics online more than in offline contexts in order to circumvent sociocultural restrictions found in an offline setting. The first scenario could also emerge when the cultural factors of 'conformity', 'adherence to religion', and 'fear of isolation' predict the offline context but do not predict or negatively predict the online context: individuals employ online platforms to evade offline limitations.

The second scenario is 'online lurking'. Proponents of this scenario believe that online media are not conducive to the expression of opinion because online communicators are passive in their communication activity, preferring only to read what others say, rather than contributing actively to online 
discussions. Many online users fail to express their opinions out of apathy and not out of fear of negative consequences. Researchers have established that people were less apt to speak about issues online (Hampton et al. 2014), that few people contribute to online political forums (Hampton et al. 2017), and that as many as 90 percent of users read online discussions but only 10 percent participate in them (van Mierlo 2014). Further research demonstrates that people are less inclined to comment online even when they are anonymous (Yun \& Park 2011) and that they are not very strongly motivated to comment even when they perceive that their opinions are in line with those of the majority (Nekmat \& Gonzenbach 2013). McDevitt et al. (2003) argue that offline contexts impose etiquette on participants in discussions that oblige them to contribute. Online anonymity and lack of social cues make people less constrained about participating in online discussions. In our study, the 'online lurking' scenario might emerge when respondents prefer to participate in offline contexts more than online. Ho and McLeod (2008), for example, attribute this condition to the impersonal and asocial nature of online platforms, which can have a moderating effect and discourage the expression of opinions. McDevitt et al. (2003: 458) argue, 'a perception of a temperate opinion climate ... provides little stimulation for provoking heartfelt opinions'.

A third 'neutral online' scenario reflects the view of scholars who contend that online platforms have no impact on whether people will express their opinions, arguing that communication behaviour in online environments is merely a reflection of their offline behaviour. They claim that online media are independent and objective conduits, and people who are expressive or inexpressive in offline settings will continue to be so in online settings. Li (2007) found that people who expressed defiance offline did the same online. Ellison et al. (2007) found that people used Facebook to foster their already established offline relationships rather than forming new ones. In this sense, people use social media to maintain and reinforce existing offline behaviours. In this study, the 'neutral online' scenario might emerge if a willingness to express an opinion offline correlates with willingness to express an opinion online or if the predictors of online expression of opinion are the same as those of offline expression of opinion. Then, this third scenario, which assumes that online communication is only a reflection of offline behaviour, would prevail.

Finally, scholars who support a fourth scenario, 'online enculturation', hold that online environments have their own unique cultural dynamics and conventions that influence the expression of opinion differently from offline environments. The nature of online cultures and groups that users join or want to be part of, their level and type of engagement, and the activities in which 
they partake in online environments affect the level of opinion expression. For example, when people follow specific online accounts, a reinforcement effect is produced, in which they are encouraged to believe that they are in a supportive opinion climate, regardless of whether this is true. This condition increases confidence and the expression of opinion and lowers fear of isolation (Schulz \& Roessler 2012). Others have argued that large online networks of followers may encourage the expression of opinion, as users believe they have many supportive followers (Hampton et al. 2014) or may at other times suppress the expression of opinion when users feel as if they are being monitored by their networks (Brandtzaeg et al. 2010). This condition not only restricts the expression of opinion but also encourages the deletion of previously posted messages and drives self-censorship (Kown et al. 2015). Those who exhibit greater online engagement may be more likely to routinely employ the conventions and norms associated with the public expression of opinion as practiced among those communities. Thus, in this study, if the daily average use of Twitter among respondents predicts different forms of expressing opinions, then it support the 'online enculturation' scenario.

The current study applies these four scenarios to examine the impact of online environments on users' willingness to express their opinions. The analysis explores aspects of each scenario: the 'cyber-optimist' scenario, which suggests that anonymity and lack of social cues in online environments will encourage greater opinion expression; 'online lurking', which considers online users as passive communicators primarily interested in obtaining information but not communicating; the 'neutral online' scenario, which reflects online communication as mere reproductions of offline behaviours; and finally the 'online enculturation' view, which argues that the online cultures that individuals join, and the activities they conduct in them, affect forms of opinion expression. Because of the absence of a definitive scenario that can theorize the expression of opinion in online contexts in a setting such as Kuwait, we raise the following research questions:

RQ1: To what extent do cultural factors, the sos's theoretical components, and Twitter variables predict the willingness to express an opinion in an incongruent online climate?

RQ2: What are the differences or similarities in the expression of opinion between an incongruent offline and online context? 


\section{$6 \quad$ Methods}

\subsection{Sample and Sampling Procedures}

The population from which the sample for this study was drawn consists of students who are the closest to the issue of schools' gender segregation because of their age and recent experience in high school and at university. The students were enrolled at either Kuwait's only public university or its oldest private, American-style university. A total of 534 students, $381(71 \%)$ at the public university and $153(29 \%)$ at the private university, volunteered to respond to a questionnaire that took approximately ten minutes to complete. The original questionnaire was translated from English into Arabic to control for any artefacts caused by language. The sample included students who were enrolled in general introductory courses, including social sciences, humanities, and natural sciences, to guarantee better representation of students in various fields of study.

\subsection{Criterion Variables}

This study uses two criteria. Both measure the willingness of individuals to express opinions in incongruent opinion climates: the first tested for an offline climate and the second for an online climate. The statement soliciting a response relating to an offline climate, adopted from Willnat et al. (2002), was modified to represent a social situation. It stated: 'Imagine you are in a social gathering and you do not know most of the people there. A group of people start discussing the issue of gender desegregation in public schools in Kuwait. How likely is it that you will express your opinion if the views of most of the people in the gathering are different from your own?' The statement relating to the online context asked the following: 'Now imagine that the issue of gender desegregation in public schools in Kuwait is being discussed or being posted about on Twitter. How likely is it that you will express your opinion if you find that the views of most of them are different from your own?' To express their attitudes towards the two previous statements, respondents used a five-point interval Likert scale from $5=$ 'extremely likely' to $1=$ 'extremely unlikely'.

\subsection{Predictor Variables}

This study has four sets of predictors. The cultural predictors are the personalities of culturally conformist and nonconformist individuals. The items were adopted from Brockner and Chen (1996). The scale reflecting conformists comprised six statements, and the scale that reflected the nonconformists had ten. Examples of the statements assessing conformity included: 'It is important to 
behave appropriately socially' and 'one should adhere to the values, beliefs, and behaviours that one's society considers acceptable'. The Cronbach's alpha measures the internal consistency or strength of the relationship between a group of items that make up a scale. A score consistency of .70 or above is the minimal acceptable level of reliability. The Cronbach's alpha reliability score for this scale was 0.70. Some of the items that were employed to assess the nonconformists were: 'One should feel free to do something even if it is considered outside of the norm' and 'I do things my way regardless of what others expect me to do'. The Cronbach's alpha score was 0.73 .

Fear of isolation included three statements, adopted from Ho and McLeod (2008). They were: 'I worry about being isolated if people disagree with me', 'I avoid telling other people what I think when there is a risk they will avoid me if they knew my opinion', and 'I feel uncomfortable if I disagree with other people'. The Cronbach's alpha score was 0.76 . For all these scales, to express their opinions, respondents used a five-point scale from 5 = 'strongly agree' to $1=$ 'strongly disagree'.

One question assessed the position of Islam on gender desegregation in schools: 'In your opinion, do you think that gender desegregation in public schools is against the instructions of Islam?' Respondents expressed their opinion by selecting 'yes', 'no', or 'I do not know'. Like other recent studies (e.g. Gearhart \& Zhang 2015) that employ a single item to assess perceptions of predominant opinion climates, this study used one item to assess perceptions about the current climate and another to measure the future climate. The item used to assess respondents' perception of the current predominant opinion was: 'Thinking about the people you normally socialize with, would most of them strongly agree, agree, be neutral, disagree, or strongly disagree with gender desegregation in public schools in Kuwait?' Respondents expressed their opinion using a five-point scale from $5=$ 'strongly agree' to $1=$ 'strongly disagree'. Perceptions of the future opinion climate, adopted from Willnat et al. (2002), were assessed using one question: 'Do you have the impression that public support for the issue of gender desegregation in public schools in Kuwait is increasing, decreasing, or staying about the same?' Response options were 'increasing', 'staying the same', and 'decreasing'.

Finally, four items examined respondents' Twitter use. Those who use Twitter often tend to be more enculturated to the platform's user community 'culture' and more subject to its rules and behavioural norms. Respondents were asked whether they had Twitter accounts. To assess the concern for anonymity by those who had Twitter accounts, they were asked whether they use their real name and photo on their Twitter accounts. Respondents could select either 'yes' or 'no'. They were also asked about their average daily use of 
Twitter. Respondents were instructed to choose one of the following options: 3 = 'often', 2 = 'sometimes', and $1=$ 'rarely'. Gender was the last predictor variable. Respondents identified themselves as male or female.

\subsection{Profile of Respondents}

Of the 534 respondents, $245(46 \%)$ were male, and $289(54 \%)$ were female. When asked whether they were conformist $(M=3.87, S D=0.57)$ or nonconformist $(M=3.89, S D=0.49)$, respondents reported moderate to high levels on both. When asked about the position of Islam on gender desegregation, 244 $(43 \%)$ of the respondents said they believed Islam was not against it, $215(38 \%)$ said it was against it, and $76(14 \%)$ said they did not know what Islam's position was on it. The level of fear of social isolation $(M=2.66, S D=0.91)$ and perception of the current opinion climate $(M=2.75, S D=1.21)$ were below average. The majority of respondents $(N=213,38 \%)$ believed that the future opinion climate in favour of segregation would decrease, $181(32 \%)$ said it would increase, and $138(24 \%)$ said it would remain the same. In all, $460(81 \%)$ of the respondents had Twitter accounts, and $74(13 \%)$ did not. Of those responding, $400(71 \%)$ said they included their real name on their Twitter account profile, and $66(12 \%)$ did not; $256(45 \%)$ included their photo on their accounts, and $208(37 \%)$ did not. Finally, 76 respondents (14\%) said they 'often' used Twitter daily, 172 (30\%) indicated 'sometimes', and 217 (38\%) said 'rarely'.

\section{$7 \quad$ Results}

\subsection{Statistical Procedures Applied to the Predictors of Opinion}

To respond to the hypotheses and research questions, we performed two multiple regression analyses. A multiple regression analysis is a statistical test to evaluate the predictability of explanatory variables (independent or factor variables) for an outcome of a response variable (dependent or criterion variable). It examines the strength of relationships between independent variables and an outcome variable in the form of a line (linear). The first regression examined the predictors of the expression of opinion in an incongruent offline context. Willingness to express an opinion about gender desegregation in public schools in an incongruent offline context was used as the dependent variable. Among the predictors, gender was in the first group of the independent variables, comprising the type of personality, being conformist, and being nonconformist; the position of Islam on the issue were in the second, and the sos's theoretical components, including fear of isolation and perceptions of 
the current and future opinion climates, were in the third group. In the second regression, which examined the expression of opinion in an incongruent online context, we followed the same procedures as for the first regression, except that the variable of willingness to express an opinion in an incongruent online context was treated as the dependent variable this time. In addition, responses indicating Twitter use were all in the fourth group of variables.

\subsection{Predictors of the Expression of Opinion in an Offline Context}

The third regression, which included all the predictors, was significant: change in $R^{2}=0.068, F(3,522)=11.61, p<0.001$. At this level, having a nonconformist personality $(\beta=0.187, t(525)=4.43, p=0.001)$ was a positive predictor, and Islam $(\beta=-0.096, t(522)=-2.27, p=0.024)$ and fear of isolation $(\beta=-0.263$, $t(522)=-6.31, p=0.001)$ were negative predictors. The results confirm $\mathrm{H} 1$ and $\mathrm{H}_{3}$. Finally, and in relation to $\mathrm{H}_{4}$, neither perceptions about current nor future opinion climates were predictors (Table 1).

To determine the differences between groups on the position of Islam, which was a negative predictor in the first regression, we performed an analysis of variance (ANOVA). ANOVA is a test that assesses the existence of statistically significant relationships between the means of more than two groups. The ANOVA between groups on the position of Islam was significant, with $F\left(2,53^{2}\right)=$ $4.37, p=0.013, \eta^{2}=0.127$. Post-hoc procedures employing Tukey's HSD (honestly significant difference) test to measure the differences in means between groups revealed that the average was higher $\left(p=0.03^{2}\right)$ among those who said Islam opposed gender desegregation $(N=215, M=4.10, S D=1.08)$ than among those who said they did not know what position is taken by Islam $(N=76, M=$ $3.74, S D=1.23)$. The average was also higher among those who said Islam did not oppose gender desegregation $(N=244, M=4.15, S D=1.01)$ than among those who did not know Islam's position $(p=0.010)$. However, no significant difference was found between those who said Islam opposed it and those who said Islam did not oppose it $(p=0.873)$. These results confirm $\mathrm{H} 2$.

\subsection{Predictors of Expression of Opinion in an Incongruent Online Context}

The regression procedure predicting the online context indicated that the analysis in the previous section, which included all predictors, was significant: $R^{2}=0.087, F(4,447)=3.87, p>0.001$. Gender $(\beta=-0.111, t(451)=-2.12$, $p=0.035)$, having a nonconformist personality $(\beta=0.135, t(451)=2.88$, $p=0.004)$, fear of isolation $(\beta=-.134, t(451)=-2.89, p=0.004)$, and the daily average use of Twitter $(\beta=-0.135, t(451)=-2.86, p=0.004)$ predicted the expression of opinion in an online context (Table 1 ). 
TABLE 1 Multiple regression analysis of the predictors of opinion expression on gender desegregation in Kuwaiti public schools in incongruent offline and online opinion climates

\begin{tabular}{|c|c|c|c|c|c|c|}
\hline \multirow[t]{2}{*}{ Predictors } & \multicolumn{3}{|c|}{$\begin{array}{l}\text { Willingness to express } \\
\text { opinion in an incongruent } \\
\text { offline context }\end{array}$} & \multicolumn{3}{|c|}{$\begin{array}{l}\text { Willingness to express } \\
\text { opinion in an incongruent } \\
\text { online context }\end{array}$} \\
\hline & $B$ & $S E B$ & $B$ & $B$ & $S E B$ & $\beta$ \\
\hline \multicolumn{7}{|l|}{ Demographic } \\
\hline Gender & -.130 & .090 &.- .060 & -.306 & .145 & $-.111^{*}$ \\
\hline \multicolumn{7}{|l|}{ Cultural predictors } \\
\hline Conformists & -.079 & .077 & -.043 & -.142 & .113 & -.058 \\
\hline Non-conformists & .404 & .091 & $.187^{* * *}$ & .382 & .133 & $.135^{* *}$ \\
\hline Islam & $-.15^{1}$ & .067 & $-.096^{*}$ & -.045 & .094 & -.022 \\
\hline \multicolumn{7}{|l|}{ Spiral's related predictors } \\
\hline Fear of isolation & -.312 & .049 & $-.263^{* * *}$ & -.205 & .071 & $-.134^{* *}$ \\
\hline $\begin{array}{l}\text { Current opinion } \\
\text { climate }\end{array}$ & .008 & .039 & .009 & .011 & .055 & .010 \\
\hline $\begin{array}{l}\text { Future opinion } \\
\text { climate }\end{array}$ & $-.05^{2}$ & .053 & -.041 & -.043 & .075 & -.027 \\
\hline \multicolumn{7}{|l|}{ Twitter's predictors } \\
\hline $\begin{array}{l}\text { Having a Twitter } \\
\text { account }\end{array}$ & & & & -.759 & .576 & -.063 \\
\hline Real name on profile & & & & .017 & .195 & .004 \\
\hline $\begin{array}{l}\text { Personal image on } \\
\text { profile }\end{array}$ & & & & .118 & $.15^{0}$ & .043 \\
\hline Twitter daily use & & & & -.254 & . & $-.135^{* *}$ \\
\hline$R^{2}$ & .135 & & & .087 & & \\
\hline Adjusted $R^{2}$ & .123 & & & .065 & & \\
\hline$F$ for change in $R^{2}$ & 13.65 & & & 2.63 & & \\
\hline
\end{tabular}

${ }^{*} p<.05,{ }^{* *} p<.01, * * * *<.001$.

The ANOva for differences between the categories of Twitter users showed that this was a predictor in the regression. ANOVA was significant, $F(2,461)=$ $5.32, p=0.005, \eta^{2}=0.15$ o. Post-hoc procedures employing Tukey's HSD revealed a lower average $(p=0.003)$ among those who said they 'often' use Twitter $(N=76, M=3.17, S D=1.46)$ than among those who said they 'rarely' used it 
$(N=216, M=3.76, S D=1.38)$. However, other tests of differences between those who responded 'often' and 'sometimes' $(p=0.07)$, and between 'sometimes' $(N=172, M=3.59, S D=1.30)$ and 'rarely', did not yield any significant differences $(p=0.44)$. With regard to RQ1, nonconformists were more likely to express their opinions online; people with a fear of isolation were less likely to express their opinions online, as were those who often used Twitter.

\subsection{Comparisons of Willingness to Express an Opinion in Offline and Online Contexts}

We conducted a single-sample independent $t$-test, used to measure differences between the means of only two groups, to explore the statistical difference in the willingness to express an opinion between incongruent offline and online contexts. The results were significant: $t(534)=87.1, p=0.001, d=0.32$. Respondents were more willing to express their opinions in an offline context $(N=534, M=4.01, S D=1.08)$ than an online context $(N=466, M=3.61$, $S D=1.38$ ). Finally, we measured the Pearson's $r$ correlations to determine the strength of relationships between two specific variables, finding a positive correlation in the willingness to express an opinion between offline and online contexts $(N=466, r=.39, p .=0.001)$ (Table 2$)$. This answers RQ2. In addition, the expression of opinion in offline and online contexts is linked.

TABLE 2 Pearson $r$ correlations

\section{Willingness to express Willingness to express opinion offline opinion in Twitter}

Willingness to express

$\begin{array}{ll}- & .392^{* * * *} \\ -.054 & -.118^{*} \\ -.036 & -.024 \\ .221^{* * *} & .166^{* * *} \\ -.079 & -.031 \\ -.296^{* * *} & -.167^{* * *} \\ -.018 & .000 \\ -.065 & -.037 \\ - & -.047 \\ - & .05^{\circ} \\ - & .121^{* *} \\ - & -.144^{* *}\end{array}$

opinion offline

Gender

Conformist personality

Non-conformist personality

Islam's standing

Fear of isolation

Perception of current climate

Perception of future climate

Twitter account

Real name on profile

Personal picture on profile

Daily use of Twitter

${ }^{*} p<.05,{ }^{* *} p<.01, * * * p<.001$. 


\subsection{Expression of Opinion in an Offline Context}

Importantly, we found that nonconformists stated they would express their opinions in an offline context regardless of the dominant conformist-oriented nature of Kuwaiti society. Conversely, respondents who were uncertain about Islam's position on gender desegregation in schools were less likely to express their opinions than those who claimed to be certain about its position. As in many earlier studies (see Scheufele \& Moy 200o), fear of isolation was not only a negative predictor of the expression of opinion in an offline context, but the strongest predictor.

Of particular importance, the identification of religious certainty and the fear of social isolation as the two biggest impediments to offline expression of opinion demonstrates the substantial impact of dominant cultural norms on the expression of opinion in Kuwait. Having to consider religious attitudes on gender desegregation when expressing an opinion in public can be worsened by the presence and influence of others in offline contexts in which people fear cultural sanctions and labelling that cast them as non-believers if they 'misspeak.' This contributes to opinion repression.

\subsection{Opinion Expression in an Online Context}

The findings pertaining to the particular variables of fear of isolation and religion in online contexts support the 'cyber-optimist' scenario, which argues that online platforms can encourage opinion expression and reduce fear of social isolation (Yun \& Park 2011). Fear of isolation was the strongest negative predictor in the offline context but was only the third strongest negative predictor in the online context; its statistical power of negative prediction drastically decreased on Twitter. This may demonstrate that people in online contexts were less afraid of cultural sanctions in online contexts than in offline settings. Further supporting this 'cyber-optimist' scenario is the measure of perceived confidence about Islam's position on desegregation. Confidence in the 'Islamic position' on this issue predicted expression of opinion in the offline context but not the online context. This suggests that religion produced fear of external cultural sanctions and that this, rather than personal beliefs and concern over feeling sinful, was driving behaviour. If this were not the case, religion would have continued to be a predictor of the online context, too.

The 'cyber-optimist' scenario is reflected in content found in the broader Arab Twittersphere. Al-Jenaibi (2016) argues that on Twitter Arabs discuss issues openly in a way that they do not in offline social contexts. Young people are making their voices heard about their neglected concerns and interests. They voice opinions because Twitter is open to a spectrum of opinions and 
news exposing the malpractice and corruption of Arab governments. Twitter activists have asked their governments to be transparent and officials to be accountable (Toska 2015). In Kuwait's neighbour, Saudi Arabia, women have demanded greater equal rights on social media. For example, many Saudi women were very active on the Twitter hashtag \#SaudiWomenRevolution and openly asked for a more active role and greater social rights. They asked for an end to many regulations that limit their basic human rights, movement, and liberty, such as requiring permission from male family members and guardians to continue their higher education, perform surgery, or open bank accounts. They also asked for the creation of laws that punish men who are violent towards women and laws forbidding marriage by females under the age of eighteen.

Although some results support a cyber-optimist scenario, the majority reflect the dominance of the scenarios of 'neutral online', 'online lurking', and 'online enculturation'. For example, the results indicated that nonconformists were willing to express their opinions in offline and online contexts and that fear of isolation, which was a negative predictor offline, remained so in online contexts. We also found a positive correlation between willingness to express an opinion in an offline context with willingness to do so in an online context. These findings combined reflect the 'neutral' scenario in which online platforms are impartial conduits that objectively reflect the nature of individuals and their social relations. If people are expressive in an offline context, they will display the same behaviour in an online context. They mostly transfer or export their existing behaviours from offline to online contexts (Ellison et al. 2007).

Again, content in the Arab Twittersphere reflects elements of the three scenarios, which suggest that, for various reasons, online media do not encourage the expression of opinion. Al-Jenaibi (2016) argues that Arab governments, especially in the Gulf region, where Kuwait is located, use laws and new cybertechniques to monitor and crack down on critical Twitter discussions. In Kuwait, Law No. 8 of 2016 regarding the Regulation of Electronic Media (Kuwait Ministry of Information 2016) has empowered the government to fine and sentence Twitter activists on charges of criticizing or ridiculing religious instructions and fundamental tenets, the ruling Amir, or other neighbouring countries. Other research (e.g. Borge-Holthoefer et al. 2015) highlights the polarized nature of the Arab Twittersphere. Aggressive Twitter communicators can disparage, label, and scold others for their opinions, pressuring those with moderate opinions to avoid expressing their opinions, which would otherwise add to the opinion spectrum or possibly temper extreme voices.

The comparative $t$-test revealed that the expression of opinion by Kuwaitis was significantly greater in the offline context than in the online context. 
Moreover, the statistical beta and significance levels for non-conformists were higher offline than online, indicating a greater interest in expressing opinions offline than online. These two findings reflect the 'lurking' scenario (Hampton et al. 2017; Nekmat \& Gonzenbach 2013).

With regard to the scenario of 'online enculturation', the average daily use of Twitter predicted online expression of opinion (in this study, it is assumed that those who report using Twitter more often are more strongly enculturated into the culture of the Twitter community). This scenario connects the expression of opinion to online culture and conventions, which individuals co-create through online interaction and engagement in a way that reconstructs the spiral's various theoretical components. The results show that people who used Twitter often were less likely to express an opinion than those who said they used it sometimes or rarely. In this regard, Twitter may have conditioned its users. Heavy Twitter users might be more committed to their followers. Because they use Twitter often, they eventually cultivate larger networks that can lead them to be cautious about expressing unpopular and culturally offensive opinions that might trigger followers to unfollow them or react with offensive and rejectionist language. Also, frequent use of Twitter can produce users who become keenly aware of the opinion trends among the perceived majority and that might regulate the expression of honest opinions. Limited Twitter users seem to care less about what others think of them. Being on Twitter for a short time makes them less encultured to online settings, less committed to their followers, less careful about maintaining their networks, and less likely to have a sense of the distribution of opinions, as they have not engaged with Twitter extensively or intensively. These findings and explanations are in line with Brandtzaeg et al. (2010) and Kown et al. (2015).

Our findings have some limitations which should be considered. The study's sample consists of university students, so they represent an age group that, on average, has a less conservative view of gender desegregation in public schools than older generations. By adopting a wider sample, future research could better reflect the influence of culture and religion in Kuwait on the expression of opinion in offline and online contexts. In addition, this study employs only a few variables for Twitter use to reflect the degree to which Twitter predicts the expression of opinion online. Future research should consider additional variables that are more reflective of the online enculturation scenario, which is likely dynamic, complex, and able to shed more light on the expression of opinion in online contexts. Finally, future research could evaluate Twitter content on the topic of desegregation to provide a comparative analysis with the current study's findings. 
In non-democratic settings, expression of opinion online might be envisaged as a venue for sharing ideas with the potential for demonstrating more inclusive sociocultural practices. However, the majority of findings in this study suggest that the sos effect still exists online, at least within the Kuwaiti Twittersphere. Some people who are characteristically expressive offline continued to be so online, but, more often, those who use Twitter frequently moderated the expression of their opinions. Others were more interested in reading the opinions of others on Twitter than in expressing their own, and most people preferred to express opinions offline rather than online. These results show that popular social media platforms, such as Twitter, might not produce measurable impacts on the scope of opinions circulated in an online environment.

The topic of gender desegregation in the Kuwaiti education system is well known to the respondents. Therefore, their general hesitation about sharing opinions on it in both online and offline contexts indicates the topic's sensitivity. Perhaps the deeply rooted nature of cultural norms makes them inherently resistant to change. Nonetheless, because these conventions are circulated through social practices that are built and maintained through communication, they are also potentially subject to change through discursive engagement. Online media hold the possibility of such engagement and can either further catalyse culturally taboo issues or infuse them with newer and alternative scenarios and ideas. When people can frequently compare the practicality of their own cultural practices against those of others, in the long run they might adopt alternatives. This process cannot begin as easily if the sos effect prevails for sensitive sociocultural topics in both online and offline contexts. When it comes to social media platforms such as Twitter, identifying the extent to which they actually foster greater expression of opinion on sensitive topics is inevitably complex, so it is too early to make any broad generalizations.

Finally, this study demonstrates that when people have more topical knowledge about sensitive issues (either for or against), they are more willing to express their own opinions. It stands to reason, then, that increased public debate over sensitive issues can embolden people to express their own views yet this is the very thing that the sos stifles. The Twittersphere does not appear to be facilitating a more robust public debate in a way that would provoke a reevaluation of the status quo, at least on the issue of gender desegregation in a Kuwaiti context. Instead, it appears to have the opposite effect. 


\section{References}

Abadeer, Adel S. (2015), Norms and Gender Discrimination in the Arab World. New York: Palgrave Macmillan.

Abdulrahim, Masoud A., Al-Kandari, Ali A., \& Hasanen, Mohammed (2009), 'The Influence of American Television Programs on University Students in Kuwait: A Synthesis'. European Journal of American Culture, 28(1), 57-74.

Al-Houlan, Walid (2015, 27 May), 'Mixture of Genders Raises a Clash'. Alrai Newspaper Online. Retrieved 28February 2019 from https://www.alraimedia.com/ article/580482/.

Al-Jenaibi, Badreya (2016), 'The Twitter Revolution in the Gulf Countries'. Journal of Creative Communications, $11(1), 61-83$.

Al-Sumait, Fahed (2014), 'Communicating Politics in Kuwait'. In: Howard, P.N. \& Hussain, M.M. (Eds.), State Power 2.0: Authoritarian Entrenchment and Political Engagement Worldwide. London: Ashgate, pp. 99-112.

Algharabali, Nada (2010), 'Two Cultures, One Room: Investigating Language and Gender in Kuwait'. PhD Thesis, Queen Mary University of London.

AlMatrouk, Lujain (2016), 'The Relationship between Gender Segregation in Schools, Self-Esteem, Spiritual Values/Religion, and Peer Relations in Kuwait'. Near and Middle Eastern Journal of Research in Education, 1(3), 2-16.

Barakat, Halim (1993), The Arab World: Society, Culture, and State. Berkeley: University of California Press.

Borge-Holthoefer, Javier, Magdy, Walid, Darwish, Kareem, \& Weber, Ingmar (2015, February), 'Content and Network Dynamics behind Egyptian Political Polarization on Twitter'. In Cosley, Dan \& Forte, Andrea (Eds.), Proceedings of the 18th ACM Conference on Computer Supported Cooperative Work \& Social Computing. Vancouver BC, pp. 700-711.

Brandtzaeg, Peter B., Luders, Marika, \& Skjetne, Jan H. (2010), 'Too Many Facebook "Friends"? Content Sharing and Sociability Versus the Need for Privacy in Social Network Sites'. International Journal of Human-Computer Interaction, 26(11-12), 1006-1030.

Brockner, Joel \& Chen, Ya-Ru (1996), 'The Moderating Roles of Self-Esteem and Self-Construal in Reaction to a Threat to the Self: Evidence from the People's Republic of China and the United States'.Journal of Personality and Social Psychology, 71(3), $6 \circ 3-615$.

Dalisay, Francis S. (2012), 'The Spiral of Silence and Conflict Avoidance: Examining Antecedents of Opinion Expression Concerning the US Military Buildup in the Pacific Island of Guam'. Communication Quarterly, 6o(4), 481-5०3. 
Dalisay, Francis, Hmielowski, Jay, Kushin, Matthew J., \& Yamamoto, Masahiro (2012), 'Social Capital and the Spiral of Silence'. International Journal of Public Opinion Research, 24(3), 325-345.

Dinkha, Juliet, Mobasher, S., \& El-Shamsy, N. (2010) 'Psychological Impact of Gender Segregation'. Psychology and Education, 47(1-2), 23-34.

Dwairy, Marwan (2006), Counseling and Psychotherapy with Arabs and Muslims: A Culturally Sensitive Approach. New York: Teachers College Press.

Ellison, Nicole B., Steinfield, Charles, \& Lampe, Cliff (2007), 'The Benefits of Facebook "Friends": Social Capital and College Students' Use of Online Social Network Sites'. Journal of Computer-Mediated Communication, 12(4), 1143-1168. Retrieved 2o October 2008 from http://jcmc.indiana.edu/volı/issue4/ellison.html. Elshahed, Heba T.S. (2014), 'Revisiting the Spiral of Silence in a Social Media Environment: Egypt's 2014 Presidential Election as a Case Study'. Master's thesis, American University in Cairo. Retrieved 2 June 2017 from: http://dar.aucegypt.edu/ handle/10526/3999/.

Fiske, Alan P. (2002), 'Using Individualism and Collectivism to Compare Cultures - A Critique of the Validity and Measurement of the Constructs: Comment on Oyserman et al. (2002)'. Psychological Bulletin, 128(1), 78-88.

Gearhart, Sherice \& Zhang, Weiwu (2015), “Was It Something I Said?" “No, It Was Something You Posted!" A Study of the Spiral of Silence Theory in Social Media Contexts'. Cyberpsychology, Behavior, and Social Networking, 18(4), 208-213.

Hampton, Keith N., Rainie, Lee, Lu, Weixu, Dwyer, Maria, Shin, Inyoung, \& Purcell, Kristen (2014), Social Media and the 'Spiral of Silence'. Washington D.C.: Pew Research Center.

Hampton, Keith N., Shin, Inyoung, \& Lu, Weixu (2017), 'Social Media and Political Discussion: When Online Presence Silences Offline Conversation'. Information, Communication \& Society, 20(7), 1090-1107.

Hasanen, Mohammed, Al-Kandari, Ali, \& Al-Sharoufi, Hussain (2014), 'The Role of English Language and International Media as Agents of Cultural Globalisation and Their Impact on Identity Formation in Kuwait'. Globalisation, Societies and Education, 12(4), 542-563.

Herb, Michael (1999), All in the Family: Absolutism, Revolution, and Democracy in the Middle Eastern Monarchies. Albany: State University of New York Press.

Herb, Michael (2002), 'Emirs and Parliaments in the Gulf'. 2002.Journal of Democracy, $13(4), 41-47$.

Ho, Shirley \& McLeod, Douglas M. (2008), 'Social-Psychological Influences on Opinion Expression in Face-to-Face and Computer-Mediated Communication'. Communication Research, 35(2), 190-207.

Hofstede, Geert (2018), Cultural Dimensions. Retrieved 3 August 2018 from https:// geert-hofstede.com. 
Huang, Huiping (2005), 'A Cross-Cultural Test of the Spiral of Silence'. International Journal of Public Opinion Research, 17(3), 324-345.

International Monetary Fund (2013), IMF Country Report: Kuwait Selected Issues. Retrieved 23 April 2014 from https://www.imf.org/external/pubs/ft/scr/2013/ cri3337.pdf.

Kamali, Mohammad H. (1997), 'Freedom of Expression Islam'. American Journal of Islamic Social Science, 10(2), 178-200.

Kown, K. Hazel, Moon, Shin-Moon, \& Stefanone, Michael A. (2015), 'Unspeaking on Facebook? Testing Network Effects on Self-Censorship of Political Expressions in Social Network Sites'. Quality \& Quantity, 49(4), 1417-1435.

Kuwait Ministry of Information (2016), 'Regulation of Electronic Media'. Retrieved 6 June 2018 from https://www.e.gov.kw/sites/kgoenglish/Forms/MediaLawo82016 .pdf.

Laffin, John (1975), The Arab Mind Considered: A Need for Understanding. New York: Taplinger.

Li, X. (2007), 'Information Exchange in the Internet and Likelihood of Expressing Deviant Views on Current Affairs in Public. San Francisco, CA: International Communication Association.

McDevitt, Michael, Kiousis, Spiro, \& Wahl-Jorgensen, Karim (2003), 'Spiral of Moderation: Opinion Expression in Computer-Mediated Discussion'. International Journal of Public Opinion Research, 15(4), 454-470.

Nekmat, Elmie \& Gonzenbach, William J. (2013), 'Multiple Opinion Climates in Online Forums: Role of Website Source Reference and Within-Forum Opinion Congruency'. Journalism \& Mass Communication Quarterly, 9o(4), 736-756.

Oyserman, Daphna, Coon, Heather M., \& Kemmelmeier, Markus (2002), 'Rethinking Individualism and Collectivism: Evaluation of Theoretical Assumptions and Meta-Analyses'. Psychological Bulletin, 128(1), 3-72.

Rani, Meesala S. \& Sumathy, Subramanain (2018), 'Online Social Networking Services and Spam Detection Approaches in Opinion Mining - A Review'. International Journal of Web Based Communities, 14(4), 353-378.

Salem, Fadi (2017), Social Media and the Internet of Things: Towards Data-Driven Policymaking in the Arab World. The Arab Social Media Report 2017 (Vol. 7). Dubai: мвR School of Government. Retrieved 20 February 2018 from https://www.mbrsg .ae/home/research.aspx.

Scheufele, Dietram A. \& Moy, Patricia (2000), 'Twenty-Five Years of the Spiral of Silence: A Conceptual Review and Empirical Outlook'. International Journal of Public Opinion Research, 12(1), 3-28.

Schulz, Anne \& Roessler, Patrick (2012), 'The Spiral of Silence and the Internet: Selection of Online Content and the Perception of the Public Opinion Climate 
in Computer-Mediated Communication Environments'. International Journal of Public Opinion Research, 24(3), 346-367.

Tetreault, Mary A. (2000), Stories of Democracy: Politics and Society in Contemporary Kuwait. New York: Columbia University Press.

Toska, Silvana (2015), 'Protest Mobilization in the Age of Twitter'. In: Al-Sumait, Fahed, Lenze, Nele, \& Hudson, Michael (Eds.), The Arab Uprisings: Catalysts, Dynamics and Trajectories. New York: Rowman \& Littlefield, pp. 135-154.

van Mierlo, Trevor (2014), 'The 1\% Rule in Four Digital Health Social Networks: An Observational Study'. Journal of Medical Internet Research, 16(2). Retrieved 13 August 2017 from https://www.ncbi.nlm.nih.gov/pmc/articles/PMC3939180/.

Willnat, Lars, Lee, Waipeng, \& Detenber, Benjamin (2002), 'Individual-Level Predictors of Public Outspokenness: A Test of the Spiral of Silence Theory in Singapore'. International Journal of Public Opinion Research, 14(4), 391-412.

World Economic Forum (2021), 'Global Gender Gap Report 2021'. Geneva: World Economic Forum. Retrieved 10 July 2021 from https://www.weforum.org/reports/ global-gender-gap-report-2O21.

World Values Survey (2014), World Values Survey. Retrieved 10 May 2020 from http:// www.worldvaluessurvey.org/wvs.jsp.

Wyatt, Robert O., Katz, Elihu, Levinsohn, Hanna, \& Al-Haj, Majid (1996), 'The Dimensions of Expression Inhibition: Perceptions of Obstacles to Free Speech in Three Cultures'. International Journal of Public Opinion Research, 8(3), 229-247.

Yun, Gi \& Park, Sung-Yeon (2011), 'Selective Posting: Willingness to Post a Message Online'. Journal of Computer Mediated Communication, 16(2), 201-227. 